\title{
TEACHING COLLABORATIVE DATA MODELING - AN APPROACH BASED ON CLOUD AND MOBILE TECHNOLOGIES
}

\section{$\underline{\text { F. Moreira, }} \underline{\text { M.J. Ferreira }}$}

\section{Universidade Portucalense (PORTUGAL)}

The proliferation of mobile devices and the increasing capabilities of these devices (built-in sensors, cameras, motion detection, location awareness, access to social networks, geospatial technologies, virtual reality, augmented reality, etc.) are changing the styles of people's lives.

The described capabilities are possible because, as shown by Tseng et al., according to International Data Corporation, the number of mobile users will increase from 174 million in 2012 to 265 million in 2016. While the use of mobile devices in the USA has truly stunning amounts:

(i) There are currently nearly 322 million mobile users, a total of approximately $100 \%$ of the population;

(ii) these mobile users, there are 256 million with a $3 \mathrm{G} / 4 \mathrm{G}$ data plane $(81 \%$ of the population);

(iii) $25 \%$ of web users are mobile only; rarely use a desktop device to access the Web.

In addition to the above data, a single person has multiple mobile devices and the number of signatures in 2013 came close to the mark of the seven billion, which is more than the world population.

Currently, there is no consensus on the cloud computing definition; however, there is consensus that the definition produced by NIST is the most suitable. A key feature of this paradigm is scalability on demand, where the user pays for the amount of services that are really used. Thus, the problems of space and sharing of documents has become a reality facilitated through the use of the cloud, particularly, Software as a Service (SaaS).

The new generation of students, according Havice, et al., grew up during the digital revolution and is technologically savvy and proficient. These students have learning styles unique, and their need for gratification instant through technology, requires that higher education institutions (HEI) revaluate their strategies regarding the teachinglearning process (TLP).

In the TLP context, and according to Ivana students equipped with a mobile device can choose to view a web page, play an audio file or watch video tutorials, send a query via SMS to their peers, or contact an expert / tutor for the guidance of the work is developing. These devices have the potential to promote learning and involvement in 
multiple form factors, conceptual and social, in and out of classrooms, even more increased their versatility by promoting learning experiences.

In this context, it is necessary to verify with this widespread availability of equipment and applications, whether it is to take proper advantage of them in the TLP. Koole raises this issue and adds the question, how can mobile learning (m_learning) be effectively implemented in both formal and informal learning? These issues are relevant, because the m_learning allows teachers and students, to have ubiquitous access to information without any constraints, since the information interaction is mediated through technology. This feature provides individualized learning opportunities, collaborative without being limited to classroom contexts.

In order to follow both trends - technology and TLP - we propose an m_learning approach to a Fundamentals of Information Systems course. In this paper it is explored the data modelling (DM) topic integrated into TLP (TLP-DM) of the BML Context Oriented (BML-CO) model with use of Lucidchart tool in a collaborative approach.

keywords: collaborative work, data modelling, cloud, mobile devices, $\underline{\text { m-learning. }}$ 